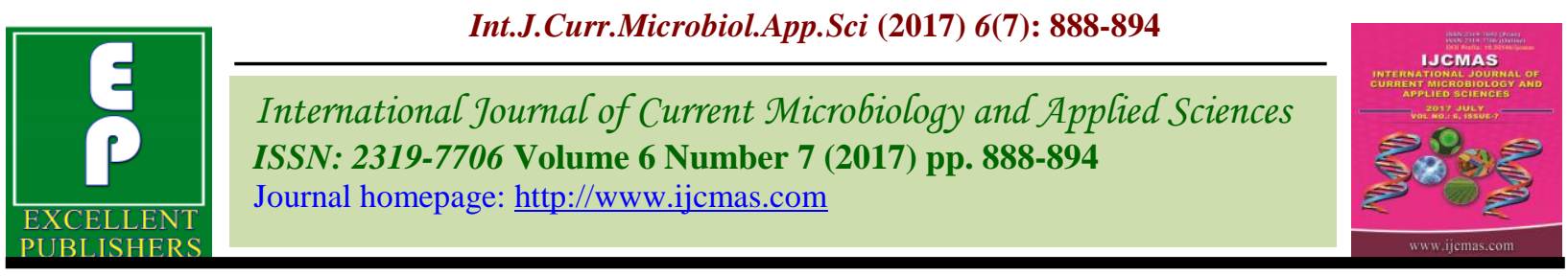

Original Research Article

https://doi.org/10.20546/ijcmas.2017.607.109

\title{
The CTX-M Type ESBL Gene Production by Klebsiella Species in Urinary Tract Infection
}

\author{
V. Mangayarkarasi ${ }^{1 *}$, K. Anitha ${ }^{1}$, D. Raja Rajeswari ${ }^{2}$ and Kalaiselvi ${ }^{1}$ \\ ${ }^{1}$ Department of Microbiology, SRM University Chennai, Tamil Nadu, India \\ ${ }^{2}$ King Institution of Preventive Medicine, Guindy, Chennai, Tamil Nadu, India \\ *Corresponding autho
}

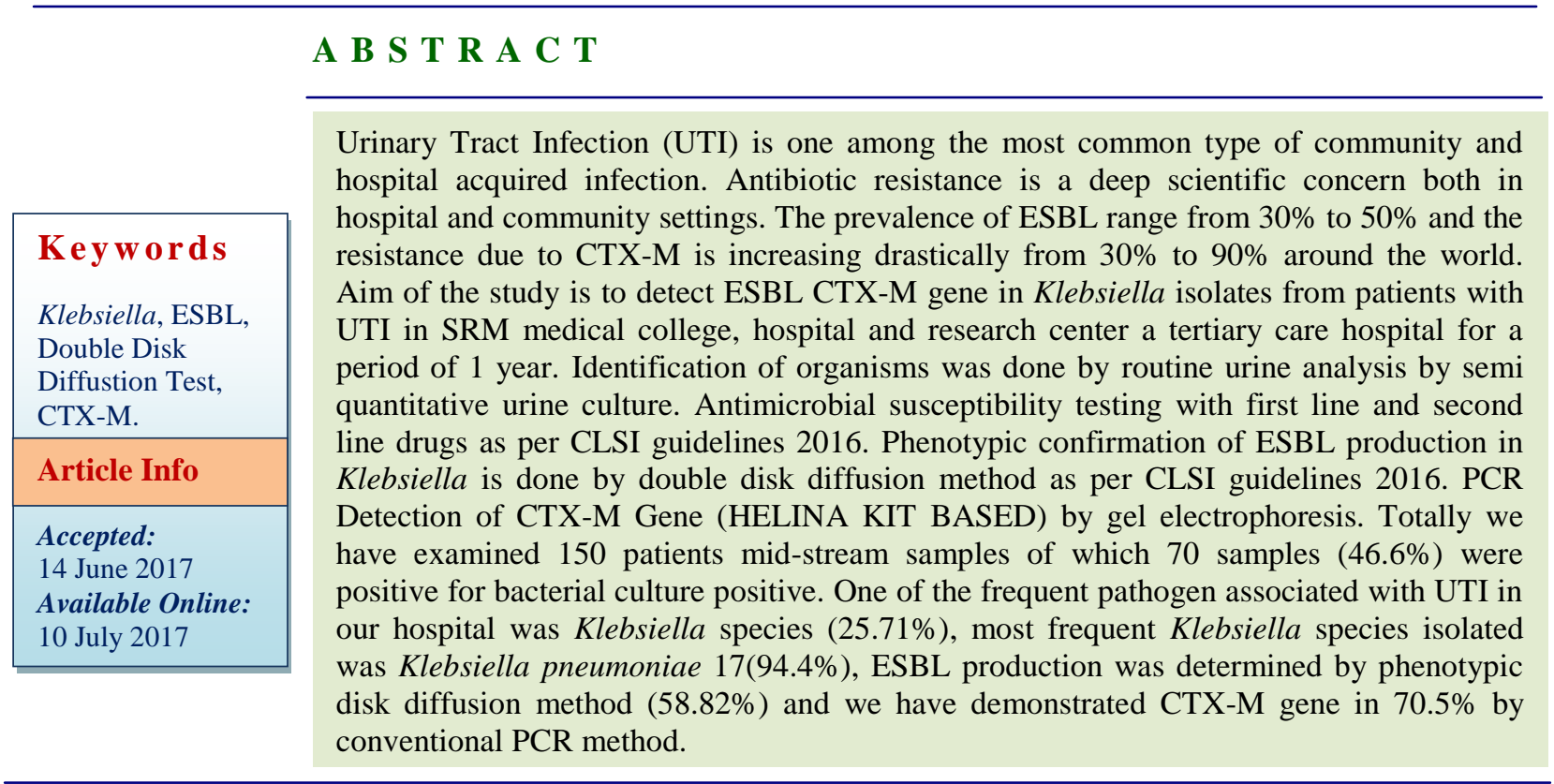

\section{Introduction}

Urinary tract infections (UTIs) have been reported to affect up to 150 million individuals worldwide every year [1] and caused mainly by Escherichia coli (68\%); Klebsiella (16.9\%); Proteus (5.5\%); Enterobacter (5.3\%); Staphylococcus saprophyticus $(2.8 \%)$; and others $(1.5 \%)$ of the isolates in India [18]. The World Health Organization and the European Commission have recognized the importance of studying the emergence and determinants of acquired anti-microbial resistance and the need to devise appropriate strategies for their control
[2-4]. Extended-spectrum $\quad \beta$-lactamases (ESBLs) have increased dramatically among clinical Enterobacteriaceae during last 3 decades. CTX-M enzymes are a group of class A extended-spectrum $\beta$-lactamases (ESBLs) that are more rapidly spreading among Enterobacteriaceae family worldwide. Since the initial isolation of CTX-M-1 from a European in the late 1980s, more than 130 CTX-M variants have been described so far. At present CTX-M family comprises 40 enzymes. The most closely related $\beta$ lactamases with identities, 62 to $75 \%$ are the 
chromosomal class A enzymes of Klebsiella oxytoca, Serratia fonticola, Proteus vulgaris, and Citrobacter koseri. These CTX-M variants are divided into 5 major phylogenetic groups, CTX-M-1, CTX-M-2, CTX-M-8, CTX-M-9 or CTX-M-25 on the basis of their amino acid sequence [5, 6, and 8]. During past decade CTX-M enzymes have become the most prevalent ESBL enzymes in clinical Enterobacteriaceae family [5, 7]. Most preferred drug for the treatment of UTI are Narrow- and extended-spectrum cephalosporins. However, management of UTIs has become increasingly problematic due to the increasing production of extendedspectrum $\beta$-lactamases (ESBLs) (Y. Huang et $a l$. ). Aim of our study is to detect Extended Spectrum $\beta$-Lactamases (ESBL) producing Klebsiella species with CTX-M gene in patients attending urology department with UTI in SRM medical college, hospital and research center a tertiary care hospital in Tamil Nadu, Kancheepuram district for a period of1 year.

\section{Materials and Methods}

We have taken 150 inpatients of urology ward with the clinical diagnosis of UTI, we collected mid-stream urine from each patient with the appropriate instruction and consent. Identification of organisms by routine urine analysis by semi quantitative urine culture with Cystine Lactose Electrolyte Deficient (CLED) agar for differentiation of lactose fermenting and non-lactose fermenting organisms and Blood agar for identification of fastidious organisms and appropriate biochemical reactions. Species differentiation of Klebsiella was done by biochemical (e.g. indole) and sugar fermentation test (e.g. lactose) [21, 22]. Antimicrobial susceptibility testing by disk diffusion method with first line and second line drugs as per The Clinical Laboratory Standards Institute Guidelines (CLSI) 2016.
Amoxycillin/Clavulanic acid (20/10 $\mu \mathrm{g})$, Piperacillin/Tazobactam (100/10 $\mu \mathrm{g})$, Cefazoline $(30 \mu \mathrm{g}), \quad$ Cefepime $(30 \mu \mathrm{g})$, Cefotaxime $(30 \mu \mathrm{g})$ Ceftriaxone $(30 \mu \mathrm{g})$, Ceftazidime $(30 \mu \mathrm{g})$, Cefaperazone/sulbactam Ertapenem $\quad(10 \mu \mathrm{g}), \quad$ Imipenem $(10 \mu \mathrm{g})$, Meropenem $\quad(10 \mu \mathrm{g}), \quad$ Gentamicine $(10 \mu \mathrm{g})$, Amikacin $(10 \mu \mathrm{g})$, Netilmicine $(30 \mu \mathrm{g})$, Ciprofloxacin $(5 \mu \mathrm{g})$, Nalidixic acid $(30 \mu \mathrm{g})$, Norfloxacin $(10 \mu \mathrm{g})$, Nitrofurantoin $(300 \mu \mathrm{g})$, Co-trimoxazole $(1.25 \mu \mathrm{g} / 23.75 \mu \mathrm{g})$.

\section{Screening for ESBL producing isolates}

All isolates showing $\leq 22 \mathrm{~mm}$ inhibition zone size for ceftazidime $(30 \mu \mathrm{g})$ and $\leq 25 \mathrm{~mm}$ inhibition zone for ceftriaxone $(30 \mu \mathrm{g})$ in the antimicrobial sensitivity test is identified as potential ESBL producers according to CLSI guidelines and subjected to double disc synergy test for phenotypic confirmation. Phenotypic confirmation of ESBL production in Klebsiella spices by double disk diffusion method.

\section{Double Disc Synergy test}

Detecting ESBL producing organism employs a beta-lactamase inhibitor clavulanate, in combination with the $3^{\text {rd }}$ Generation Cephalosporins (3GC) such as ceftriaxone and cefotaxime. A bacterial suspension of potential ESBL with 0.5 Mcfarland turbidity standard is inoculated on the MHA plate, ceftazidime $(30 \mu \mathrm{g})$ disc, ceftriaxone $(30 \mu \mathrm{g})$ discs are placed at a distance of $20 \mathrm{~mm}$ from ceftazidime + clavulanic acid $(30 \mu \mathrm{g} / 10 \mu \mathrm{g})$, ceftriaxone + clavulanic acid $(30 \mu \mathrm{g} / 10 \mu \mathrm{g})$ respective and incubated under $37^{\circ} \mathrm{c}$ for $16-18$ hours.

Positive result- difference of $\geq 5 \mathrm{~mm}$ in the zone diameter for ceftazidime +clavulanic acid against ceftazidime or ceftriaxone +clavulanic acid against ceftriaxone. 
Negative result- difference of $\leq 4 \mathrm{~mm}$ in the zone diameter for ceftazidime + clavulanic acid against ceftazidime or ceftriaxone + clavulanic acid against ceftriaxone.

\section{Conventional Polymerase Chain Reaction (PCR) detection of CTX-M}

DNA extraction and the PCR procedure was done in King Institution of Preventive Medicine, Gundy (HELINA KIT BASED): Cells are lysed during a short incubation with proteinase $\mathrm{K}$ in the presence of chaotropic salt, which immediately inactivates all the nucleases. Cellular nucleic acids bind selectively to special glass fibers prepacked in the pure fast purification filter tube. Bound nucleic acids are purified in series of rapid "wash and spin" steps to remove contaminating cellular components. Finally low salt elution releases the nucleic acid for the glass fiber. The primer sequencing of CTX-M gene is given in table 1 .

\section{PCR product size is almost 276 base pair}

The product of amplified DNA from PCR is added to the wells prepared (2\% agarose gel) and subjected to electrophoresis using TAE buffer at 50v. Gel viewed in UV transiluminator and documented (Table 2 and Fig. 1).

\section{Results and Discussion}

Out of 150 patient's urine samples 70 samples (46. 6\%) were bacterial cultures were positive. Among the culture positive E. coli was the most isolated organism accounting for $23(33 \%)$. The second commonest isolate was Klebsiella species accounted for 18 (26 $\%)$. Followed Pseudomonas aeruginosa $5(7 \%)$, Gram positive cocci accounted for 24(34\%). In the isolated Klebsiella species was Klebsiella pneumoniae 17 (94.4\%) and one species was Klebsiella oxytoca. Table 3 explains the gender distribution of culture and Klebsiella positive isolates.

The following drugs were increasingly used by the department of urology in hospital due to high degree of sensitivity (Chart 1).

By double disk diffusion test 10 isolates were positive for ESBL production among Klebsiella species isolated. When it was subjected to molecular detection by conventional PCR Detection of CTX-M Gene in gel electrophoresis, the finding shows CTX-M (7) among ESBL producing Klebsiella species is $70 \%$.

The present study, done on molecular aspect is aimed at screening ESBL producing Klebsiella species with CTX-M genes. This study found out resistance due to ESBL producing Klebsiella species is increasing and the most prevalent gene in circulation is CTX$\mathrm{M}$ in this geographical our area. In the present study, majority of the cases were from males compared to females. Study by Eshwarappa et $a l$., in south India also showed similar results [19] (Table 4).

E. coli was the most isolated organism accounting for 23 (33\%). The second commonest isolate was Enterococci 19(27\%) followed by Klebsiella pneumoniae which accounted for $18(26 \%)$.

Similar to the study by Varghese et al., showed E. coli (48\%), Klebsiella pneumoniae (17\%) followed by Candida species (10\%) and other Klebsiella species (2\%) [8].

Klebsiella species which are harboring ESBL may usably acquire additional resistance to some group of antibiotics like trimethoprim, aminoglycosides tetracylines, co-trimoxazole, and quinolones [9]. 
Table.1 CTX-M type ESBL gene primer

\begin{tabular}{|l|l|}
\hline Gene Detected & Primer \\
\hline bla CTX-M & F-ACGTGGCGATGAATAAGCTG \\
& R-AACCCAGGAAGCAGGCAGT \\
\hline
\end{tabular}

Table.2 PCR amplification protocol

\begin{tabular}{|l|l|l|}
\hline PCR amplification protocol & Time & Temperature \\
\hline Initial Denaturation & $5 \mathrm{~min}$ & $95^{\circ} \mathrm{C}$ \\
Denaturation Annealing & $30 \mathrm{sec}$ & $95^{\circ} \mathrm{C}$ \\
Extension & $30 \mathrm{sec}$ & $58^{\circ} \mathrm{C}$ \\
Final extension & $30 \mathrm{sec}$ & $72^{\circ} \mathrm{C}$ \\
& $5 \mathrm{~min}$ & $72^{\circ} \mathrm{C}$ \\
\hline
\end{tabular}

Table.3 Gender distribution of the study population

\begin{tabular}{|l|l|l|}
\hline $\begin{array}{l}\text { Number (\%) of patients with } \\
\text { clinical diagnosis with UTI }\end{array}$ & $\begin{array}{l}\text { Number (\%) of bacterial } \\
\text { culture positive }\end{array}$ & $\begin{array}{l}\text { Number }(\%) \text { of Klebsiella } \\
\text { species in bacterial culture } \\
\text { positive }\end{array}$ \\
\hline MEN(104) & $50(71.5)$ & $12(66.7)$ \\
\hline WOMEN (46) & $20(28.5)$ & $6(33.3)$ \\
\hline TOTAL (150) & 70 & 18 \\
\hline
\end{tabular}

Table.4 Phenotypic and genotypic detection of ESBL

\begin{tabular}{|l|l|l|}
\hline $\begin{array}{l}\text { Klebsiella } \text { species isolated in } \\
\text { bacterial culture positive }\end{array}$ & $\begin{array}{l}\text { Among Klebsiella } \text { species } \\
\text { isolated ESBL detection by } \\
\text { double disk diffusion test }\end{array}$ & $\begin{array}{l}\text { Among ESBL Klebsiella } \\
\text { species CTX-M Gene } \\
\text { detection by PCR }\end{array}$ \\
\hline $18(24.4 \%)$ & $10(58.82 \%)$ & $7(70 \%)$ \\
\hline
\end{tabular}

Fig.1 DNA ladder

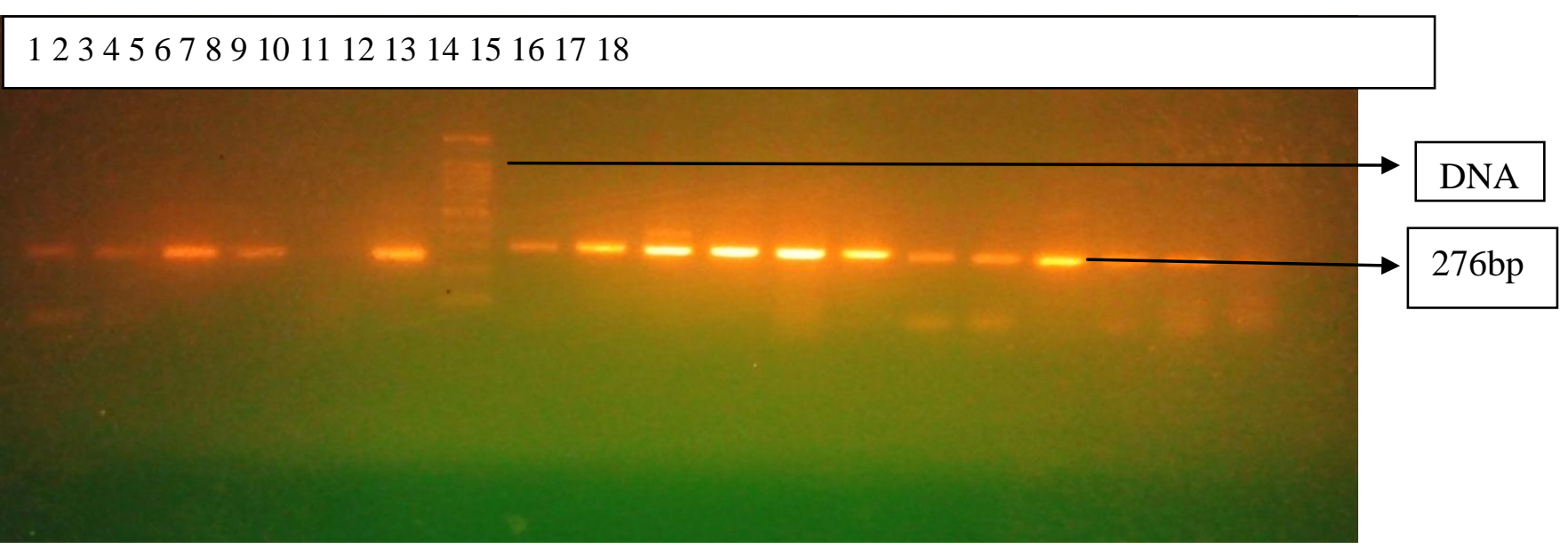


Chart.1 Antibiotic sensitivity pattern of Klebsiella species

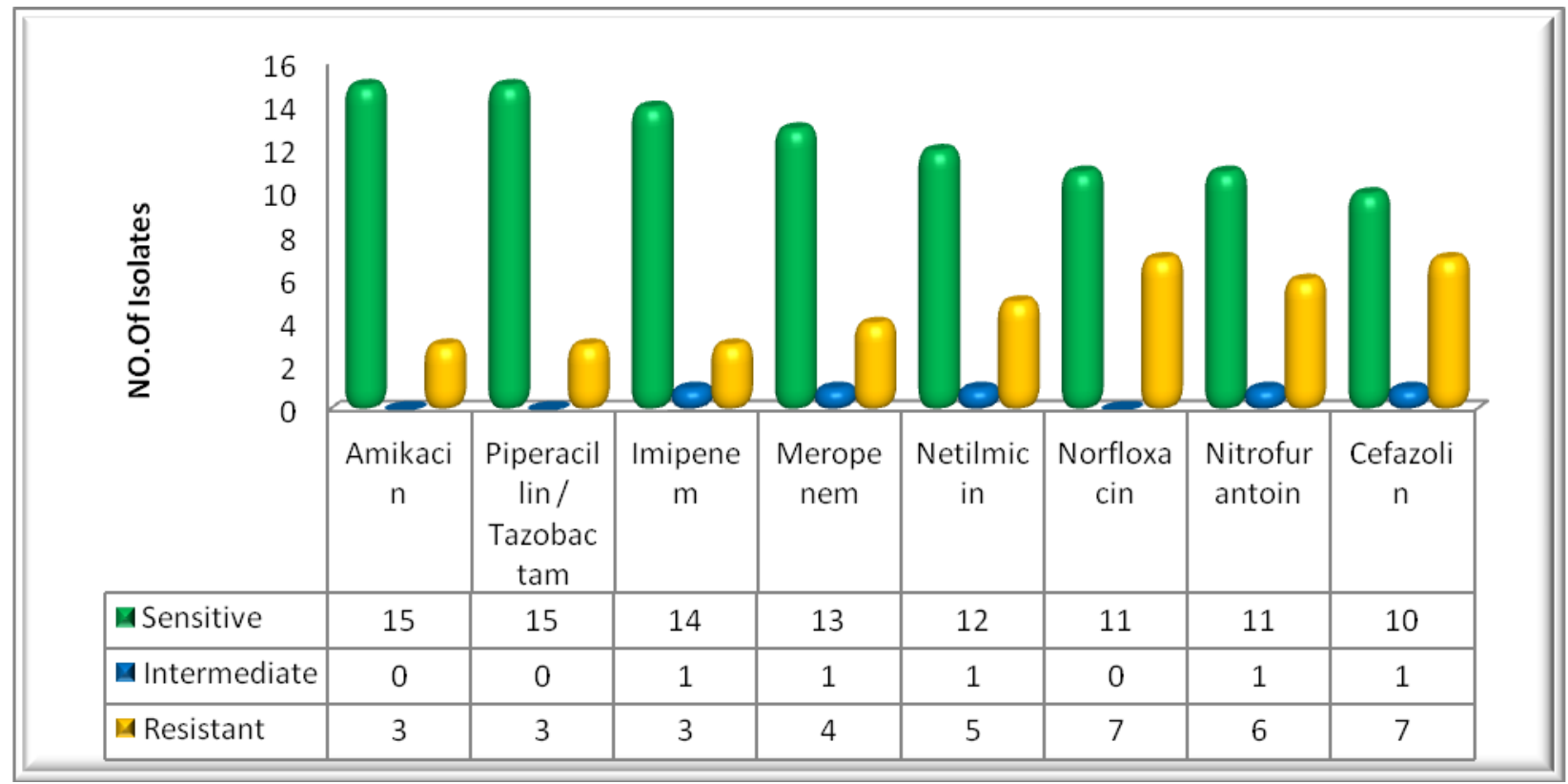

The antimicrobial suitability showed that amikacin and piperacilin tazobactem as the most sensitive drugs for Klebsiella species.

Antibiotic susceptibility pattern shown by the Enterobacteriaceae isolates were variable. Amikacin (83\%), piperacillin tazobactam $(83 \%)$ and Imipenem $(78 \%)$ was the most effective antibiotic for the isolates similar to the study by Yadav et al., [10] and Xiao et al., [12].

The Multi-drug resistant in $K$. pneumoniae has recently emerged as a troublesome pathogen worldwide. Resistances caused by ESBLs are mainly responsible for the drug resistance to $\beta$-lactam antibiotics Liu et al.,; Lahlaoui et al., [11].

The proportion of ESBL-producing $K$. pneumoniae (56\%) in this study was higher than that in Italy (32.6\%), America (51.8\%), Korea $(52.9 \%)$, and lower than Russia (60.8\%) Kim et al., [13]; Edelstein et al.,[14]; Marra et al.,[15]; Tumbarello et al.,[16], and the dominate ESBL enzyme CTX-M (70\%) of ESBL producers were similar Edelstein et al., $[15,12]$.
In other studies conducted in Iran and Beijing showed ESBL detection of (59.20\%) and $(32.21 \%)$.The rate of detection of ESBLs in the present study with $K$. pneumoniae was calculated to be $56 \%$; which was lower than the rate observed in Iran (59.20\%), and higher than that seen in Beijing (32.21\%). However, the rate of detection of CTX-M ESBLs in ESBL producing $K$. pneumoniae $(70 \%)$ was lower than that seen in Beijing (84.80\%), and higher than that in Iran (23.90\%) [22- 24].

Antibiotic resistance is a problem of deep scientific concern both in hospital and community settings. Rapid detection in clinical laboratories is essential for the recognition of antimicrobial resistant organisms. Production of extended-spectrum $\beta$-lactamases (ESBLs) is a significant resistance-mechanism that impedes the antimicrobial treatment of infections caused by Gram negative bacteria and is a serious threat to the currently available antibiotics, 
and resistance by CTX-M is increasing. Proper infection control practices and barriers are essential to prevent spread and outbreaks of ESBL producing bacteria.

\section{Acknowledgment}

We would like than SRM university Department of microbiology. We would like to thank King Institute of preventive medicine Department of Bacteriology to provide the facilities to do molecular work.

\section{References}

Stamm WE., 1999. The epidemiology of urinary tract infections: Risk factors reconsidered. Inter Sci Conf Antimicrob Agents Chemother.39, 769

World Health Organization. Report on infectious diseases 2000: overcoming antimicrobial resistance. Available from: http://www.who.int/infectiousdisease-report/index.html

Centers for Disease Control and Prevention. Preventing emerging infectious diseases. http://www.cdc.gov/ncidod/ emergplan/plan98.pdf.

European Community., 13/07/1999, A strategy against the microbial threat. Official Journal of the European Community. Council Resolution of 8 June 1999 on antibiotic resistance. Official Journal C 195. p. 1-3.

Rossolini GM, D'Andrea MM, MugnaioliC.etal., 2008, The spread of CTX-M-type extended-spectrum betalactamases. Clin Microbiol Infect. 14(Suppl 1):33- [6] Bonnet R., 2004, Growing group of extended-spectrum beta-lactamases: the CTX-M enzymes. Antimicrob Agents Chemother. 48:1-14 10.1128/AAC.

Paterson DL, Hujer KM, Hujer AM, Yeiser B, et al., 2003. Extended-spectrum betalactamases in Klebsiella pneumoniae bloodstream isolates from seven countries: dominance and widespread prevalence of SHV- and CTX-M-type beta-lactamases. Antimicrob Agents Chemother.47,3554-6010.

Varghese, A., George, S., Gopalakrishnan, R., et al., 2016, Antibiotic susceptibility pattern of Klebsiella pneumoniae isolated from cases of urinary tract infection in a tertiary care setup.J. Evolution Med.Dent.Sci.5(29),14701474.

Maina D, Makau P, Nyerere A, Revathi G., 2013, Antimicrobial resistance patterns in extended-spectrum $\beta$-lactamase producing Escherichia coli and Klebsiella pneumoniae isolates in a private tertiary hospital, Kenya. Microb Discov.1,5.

Yadav, Kamlesh Kumar et al., 2017, "Multidrug Resistant Enterobacteriaceae and Extended Spectrum B-Lactamase Producing Escherichia coli: A Cross-Sectional Study in National Kidney Center, Nepal." Antimicrobial Resistance and Infection Control 4 (2015). 42.

JingjingQuan, Dongdong Zhao, Lilin Liu, Yan Chenet al., 2017, High prevalence of ESBL-producing Escherichia coli and Klebsiella pneumoniae in community-onset bloodstream infections in China. $\mathrm{J}$ Antimicrob Chemother.72 (1): 273-280.

Xiao, Shu-zhen et al., 2017, "The Resistance Phenotype and Molecular Epidemiology of Klebsiella pneumoniae in Bloodstream Infections in Shanghai, China, 2012-2015." Frontiers in Microbiology8 (2017). 250.

Kim Y. K., Pai H., Lee H. J., Park S. E., et al.,2002, Bloodstream infections by extended-spectrum $\quad \beta$-lactamaseproducing Escherichia coli and Klebsiella pneumoniae in children: epidemiology and clinical outcome. 
Antimicrob. Agents Chemother. 46, 1481-1491.

Edelstein M, Pimkin M, Palagin I, Edelstein I, et al., 2003M, Prevalence and molecular epidemiology of CTX-M extendedspectrum beta-lactamase-producing Escherichia coli and Klebsiella pneumoniae in Russian hospitals. Antimicrob Agents Chemother. 47(12),3724-32.

Marra AR, Wey SB, Castelo A, Gales AC,et al., 2006, Nosocomial bloodstream infections caused by Klebsiella pneumoniaee: impact of extendedspectrum beta-lactamase (ESBL) production on clinical outcome in a hospital with high ESBL prevalence. Infect Dis.14.6(2), 24.

Tumbarello M, Spanu T, Sanguinetti M, Citton R., 2006, Bloodstream infections caused by extended-spectrum-betalactamase-producing Klebsiella pneumoniaee: risk factors, molecular epidemiology, and clinical outcome. Antimicrob Agents Chemother. 50(2),498-504.

Kaur, Maninder, and Aruna Aggarwal., 2013, "Occurrence of the CTX-M, SHV and the TEM Genes Among the Extended Spectrum B-Lactamase Producing Isolates of Enterobacteriaceae in a Tertiary Care Hospital of North India." Journal of Clinical and Diagnostic Research : JCDR 7.4 (): 642-645.

Kothari, Sagar et al., 2008, -Antibiotic resistance in pathogens causing community acquired urinary tract infections in India: a multicenter studyl J Infect Developing Countries, 354-358. Koneman, Procop, Schreckenberger, Woods., 2006 - Winn W Koneman E. Koneman colour atlas and textbook of diagnostic microbiologyl 6 Edition, Lippincott Williams \&Wikins, Philadelphia. 1443-1449

Mohammed Akram, Mohammed Shahid et al., 2007 -Etiology and antibiotic resistance patterns of communityacquired urinary tract infections in $\mathrm{J} \mathrm{N}$ M C Hospital Aligarh, Indiall Annals of Clinical Microbiology and Antimicrobials, 6

Bailey, scott., 2014 "Bailey \& Scott's diagnostic microbiology" 10 Edition: Elsevier: pp 919-929

Feizabadi MM, Delfani S, Raji N, Majnooni A, et al., 2010, Distribution of bla(TEM), bla(SHV), bla(CTX-M) genes among clinical isolates of Klebsiella pneumoniae at Labbafinejad Hospital, Tehran, Iran. Microb. Drug Resist; 16, 49-53.

Ghafourian S, Bin Sekawi Z, Sadeghifard N, Mohebi R, et al., 2011, The prevalence of ESBLs producing Klebsiella pneumoniae isolates in some major hospitals, Iran. OpenMicrobiol.J.5, 9195

Zou LK, Wang HN, Zeng B, Zhang AY, et al., 2011Phenotypic and genotypic characterization of $\beta$-lactam resistance in Klebsiella pneumoniae isolated from swine. Vet. Microbiol.149, 139-14.

\section{How to cite this article:}

Mangayarkarasi, V., K. Anitha, D. Raja Rajeswari and Kalaiselvi. 2017. The CTX-M Type ESBL Gene Production by Klebsiella Species in Urinary Tract Infection. Int.J.Curr.Microbiol.App.Sci. 6(7): 888-894. doi: https://doi.org/10.20546/ijcmas.2017.607.109 